\title{
O PROCESSO ENSINO-APRENDIZAGEM NA FORMAÇÃO DE TRABALHADORES DO SUS: REFLEXÕES A PARTIR DA EXPERIÊNCIA DA ETSUS
}

\author{
THE TEACHING-LEARNING PROCESS IN TRAINING NHS WORKERS: REFLECTIONS FROM THE \\ EXPERIENCE OF ETSUS
}

\author{
EL PROCESO ENSEÑANZA-APRENDIZAJE EN LA FORMACIÓN DE TRABAJADORES DEL SUS: \\ REFLEXIONES A PARTIR DE LA EXPERIENCIA DE LA ETSUS
}

\author{
Márcia Cristina Godoy Siqueira ${ }^{1}$ \\ Maria Tereza Leopardi ${ }^{2}$
}

Resumo Apresenta-se neste texto os resultados de uma pesquisa cujo objetivo foi avaliar o desenvolvimento do processo de ensino e aprendizagem, sustentado por metodologia participativa problematizadora, na perspectiva de professores e alunos da Escola Tocantinense do Sistema Único de Saúde Dr. Gismar Gomes para formação de trabalhadores desse sistema e para os que buscam o ingresso neste mercado de trabalho. Optamos pelo 'itinerário de pesquisa' do educador Paulo Freire, adotando os 'círculos de cultura' como contexto de coleta de dados, com três etapas: construção dos temas geradores; codificação e decodificação dos temas; e desvelamento crítico. Foram identificadas as temáticas: problematização como opção metodológica; aplicação da me-todologia problematizadora; desafios do processo de ensino-aprendizagem; e fatores que o dificultam ou facilitam o processo de ensino-aprendizagem. Este processo possibilitou maior aproximação entre os diversos participantes e permitiu problematizar aspectos do processo de ensino-aprendizagem da escola, favorecendo melhor compreensão desta realidade, permitindo recontextualizá-la com novas possibilidades, avanços e meios de superação.

Palavras-chave educação profissionalizante; formação de recursos humanos; ensino-aprendizagem.
Abstract This paper presents the results of a study carried out to evaluate the development of teaching and learning, supported by a problem-based participatory approach, from the perspective of professors and students of the Escola Tocantinense do Sistema Único de Gismar Gomes, in training National Health System workers and those seeking to enter this labor market. We opted for the 'research itinerary' approach set forth by educator Paulo Freire, adopting 'crop circles' as data collection framework, in three stages: Construction of generating themes; encoding and decoding of the issues, and critical unveiling. These themes were identified: Problematization as a methodological option; application of the investigative methodology; challenges in the teaching-learning process, and factors that hinder or facilitate the teaching-learning process. This process enabled closer relations among the various participants and allowed discussions on aspects of the school teaching-learning process, affording a better understanding of this reality, allowing it to be re-contextualized with new possibilities, progress, and means to overcome.

Keywords Vocational education; training of human resources; teaching and learning. 


\section{Introdução}

Este tema não é novo em si. Ainda não satisfeitas com muitas das proposições encontradas na literatura, pensamos em compreendê-lo por meio de pesquisa realizada na Escola Tocantinense do Sistema Único de Saúde Dr. Gismar Gomes (ETSUS). Muitos trabalhadores da área da saúde envolvidos com o processo de formação profissional entendem a necessidade de mudanças nas práticas docentes, mas em geral estão despreparados para promovê-las.

Nessa linha argumentativa, acreditamos que professores e alunos, muitas vezes próximos às metodologias tradicionais, podem aprender a romper com paradigmas educacionais e da saúde ainda vigentes, por meio de um processo de reflexão problematizadora. Nosso desafio foi realizar a investigação como processo de aprendizagem, de modo que a metodologia considerada como fundamento pedagógico da instituição pudesse ser testada concretamente pelos participantes.

No Dicionário da Educação Profissional (Coelho, 2009), encontramos a informação histórica de que já em manuscritos egípcios de 1650 a.C., e chineses de 1000 a.C., fazia-se menção à necessidade de reconhecimento de problemas, cuja sistematização desenvolveu-se a partir de ideias de John Dewey, na virada no final do século XIX.

Além deste autor, os brasileiros Saviani e Freire se ocuparam em traduzir a formulação de Dewey para a realidade da formação do povo brasileiro, introduzindo a problematização crítica da realidade como modo de desenvolvimento da cidadania.

No final da década de 1970, já se falava da inadequação da formação dos profissionais para atuarem no sistema de saúde, mediante o argumento de que as escolas profissionais não atendiam as necessidades do setor. Para os críticos dessa época, as referidas escolas estavam pautadas no modelo biomédico, apresentando uma discrepância entre o ensino e as necessidades do Sistema Único de Saúde (SUS) (Cutolo, 2006; Almeida e Ferraz, 2008).

Atualmente, tal processo de formação procura outro caminho, considerando concepções pedagógicas participativas e integradoras. Em nosso entendimento, as diretrizes do SUS são intrinsecamente coerentes com proposições de construção de cidadania em todos os momentos da trajetória das pessoas como usuárias deste sistema.

Por outro lado, promoção, prevenção e recuperação da saúde estão implicadas necessariamente com ações educativas, consistentes com a proposta da Reforma Sanitária, no sentido de superação do modelo biomédico, que não considera o contexto de relações sociais e particulares que constituem o substrato para o desenvolvimento da vida, do adoecimento e das formas de atenção necessárias à promoção e manutenção da saúde. 
Ainda, a formação profissional deve ser pautada no sentido de reorientar e qualificar a prática profissional, com vistas à integralidade das ações, privilegiando os conhecimentos, experiências e expectativas do sujeito em formação como ponto de partida do processo ensino-aprendizagem (Sorio, 2002; Brasil, 2006; Cutolo, 2006).

Construídas com esse propósito, as escolas técnicas de saúde do SUS (ETSUS) têm se esforçado para considerar a realidade do aluno nas experiências de ensino, para que ele se sinta desafiado a buscar novos conhecimentos e estratégias, desenvolvendo, com isso, sua criatividade, criticidade e competência, com capacidade para compreender a realidade e suas possibilidades de transformação.

Desta forma, cada vez mais, novos saberes e práticas são requeridos dos trabalhadores, sendo-lhes exigida capacidade de diagnóstico e de solução de problemas, criatividade e proatividade na tomada de decisões, no trabalho em equipe e no enfrentamento de situações de mudanças, além de serem eficazes, eficientes e efetivos no processo de trabalho (Brasil, 1999; Sorio, 2002).

Contudo, há dois aspectos que precisam ser considerados. Os docentes da ETSUS são profissionais da saúde e não foram formados para exercer a docência, mas sim a assistência ou a gestão na saúde. Por outro lado, trabalham em instituições onde prevalece, ainda, o modelo biomédico, centralizado no médico, reproduzindo a relação hierárquica entre os que sabem e os que não sabem, da mesma forma que na escola tradicional na qual foram formados eles mesmos.

Apesar de seus esforços para superar sua própria história como sujeitos, reproduzem a mesma relação verticalizada tanto em sala de aula como nos ambientes de assistência, não havendo, como regra geral, espaço para questionamentos sobre a integralidade e eficácia das ações.

Além disso, os conteúdos na área da saúde geralmente são bastante técnicos e os currículos vêm sendo construídos pela equipe da ETSUS de forma fragmentada, com excesso de informações, dificultando a problematização das vivências.

Dada à relevância do assunto e visando viabilizar uma nova possibilidade de formação profissional, faz-se necessário conhecer com maior profundidade como o processo de ensino-aprendizagem ocorre nas ETSUS e qual a importância e implicação da utilização de uma metodologia problematizadora.

No entanto, o método adotado por uma escola, por si mesmo, não fará diferença, a menos que seja um caminho conscientemente trilhado pelos participantes, como processo em constante atualização, em termos de meios e fins, sem o que tornar-se-á apenas mais uma nova verdade, que se admira mas não se compreende e não se vive.

Acreditamos que o processo participativo é condição sem a qual não há aprendizagem significativa e nem há construção de conhecimento. Charlot 
(2000, p. 68) afirma que "o espaço do aprendizado é, (...), um espaço-tempo partilhado com outros homens, é, portanto, um espaço participativo".

Neste espaço, a comunicação horizontal entre os participantes deverá ser considerada sob uma perspectiva de mutualidade de interesses, em presença de uma diversidade de experiências individuais, ou seja, as diferenças óbvias entre seres humanos com histórias peculiares são expostas como possibilidades para o aprendizado compartilhado.

O movimento de adesão a metodologias ativas, com o intuito de substituir aquelas existentes na escola tradicional, tem aumentado nas últimas décadas, para superar o ato pedagógico sustentado na memorização, autoridade exacerbada dos docentes e participação discente extremamente limitada.

Essas novas propostas têm encorajado inúmeros educadores a transformar sua prática pedagógica, implicando-a com a realidade dos estudantes, tanto do ponto de vista psicológico, cognitivo, afetivo, como sociocultural e, a partir desta compreensão, buscar novas formas de ensinar e de aprender.

Entretanto, é importante considerar que encontramos aprendizes que buscam a escola com motivações diferentes, com características e saberes próprios, tornando-se um grande desafio ao professor que teve formação tradicional e fragmentada, quando se propõe a enxergar seu aluno em sua totalidade e concretude (Mahoney e Almeida, 2005).

Considerando os processos de mudança do ensino em saúde, a pedagogia da problematização das vivências tem sido considerada um caminho adequado para a formação integral da pessoa, na medida em que se volta para a construção do conhecimento no contexto de uma formação crítica, estimulando a gestão participativa dos protagonistas da experiência e a reorganização da relação teoria/prática.

Segundo Bordenave e Pereira (2004), com esta abordagem, o aluno aprende a 'ver' sua realidade e é estimulado a transformá-la, a ter uma visão integradora e dialética, com alto grau de motivação endógena. Aprende a trabalhar em grupo, a desenvolver a capacidade de crítica e de autocrítica, a teorizar com base em sua própria observação, a desenvolver a criatividade e a originalidade, aprendendo a inovar, buscando informação de forma autônoma.

Por outro lado, sucessivas aproximações com a metodologia problematizadora fazem com que, aos poucos, os professores tornem-se mais seguros e confiantes. Eles percebem que é viável, mas, acima de tudo, necessário romper com o ensino fragmentado.

Os trabalhadores-aprendizes, na maioria das vezes, encontram-se desarticulados na prática do trabalho, nem sempre recebendo educação permanente, o que proporcionaria um lastro informativo e formativo mais compatível com as exigências de uma proposta participativa e emancipadora.

Dada a relevância do assunto, visando viabilizar novas possibilidades de práticas pedagógicas, é necessário conhecer com maior profundidade 
como o processo de ensino-aprendizagem ocorre e qual a importância e implicações consequentes da metodologia adotada pela ETSUS. Para tanto, o principal objetivo desta pesquisa constituiu-se em compreender e analisar como vem sendo desenvolvido o processo de ensino e aprendizagem, com a utilização da pedagogia problematizadora, na visão dos docentes e discentes da ETSUS.

Para tanto, pretendíamos conhecer as percepções de docentes e alunos no processo de ensino e aprendizagem frente as necessidades de assistência qualificada e avaliar elementos facilitadores e dificultadores para a efetiva aplicação da metodologia problematizadora.

\section{Círculos de cultura, o caminho metodológico}

A metodologia utilizada no desenvolvimento desta pesquisa fundamentou-se nos 'círculos de cultura', propostos pelo educador Paulo Freire, em seu método de investigação denominado itinerário de pesquisa, adotado com sucesso entre educadores e educandos.

O método Paulo Freire de investigação tem coerência com suas ideias e consiste de três momentos conectados, que ele chamou de itinerário de pesquisa. Podemos dizer que a investigação se interessa pela realidade na qual os participantes do processo ensino-aprendizagem estão inseridos, por meio da compreensão dos elementos da linguagem cotidiana, nos círculos de cultura.

Gadotti (1991) descreve o círculo de cultura como uma unidade de ensino formado por um grupo de pessoas que se reúne para discutir seu trabalho, a realidade local, sua vida nesta realidade, e assim por diante.

Saupe, Brito e Giorgi (1998) relatam várias experiências relativas aos círculos de cultura e dizem que essa proposta representa uma alternativa para aqueles que desejam mudanças e aperfeiçoamentos, por ser a expressão de um momento riquíssimo para o exercício dialógico.

Como preconizado por Freire, o itinerário de pesquisa desenvolveu-se em três etapas. Na primeira etapa, foi feito um levantamento dos temas geradores ou etapa da investigação temática, que compreende a busca de temas ou palavras, extraídos do universo do cotidiano dos componentes do círculo de cultura, durante uma experiência de troca de ideias. A identificação dos temas pode partir do mais geral ao mais específico (Freire, 1994); Gadotti, 1991). Atentas às falas, investigando o pensar e o agir dessas pessoas, fizemos algumas perguntas desencadeadoras pertinentes ao objeto de pesquisa, levando as pessoas a compartilharem suas experiências reais, nas quais pudemos apreender aspectos que retratavam sua compreensão da metodologia problematizadora em seu cotidiano. 
Na segunda etapa, partiu-se para a codificação e decodificação dos temas geradores. Com os temas geradores identificados, ocorreu o momento em que todos compartilharam sua avaliação sobre o assunto, ou seja, codificando e decodificando a linguagem na qual se expressaram para relatar suas experiências. Nesta etapa, foram proporcionados momentos de teorização aos participantes do círculo de cultura, em idas e vindas do concreto para o abstrato e do abstrato para o concreto. Esta é uma ação necessária para que as pessoas possam enxergar e analisar fenômenos, processos e coisas (Brandão, 1994; Freire, 1994; Gadotti, 1991).

A terceira etapa consiste no desvelamento crítico. Procuramos evidenciar, nessa última fase, a percepção dos participantes sobre como a realidade se apresenta e quais são as possibilidades de mudança e superação. O objetivo final do método é a conscientização. Conhecendo as coisas a fundo e descobrindo o que tem no seu interior, pode-se transformá-las (Brandão, 1994; Freire, 1994); Gadotti, 1991).

A temática desta pesquisa atendeu aos requisitos necessários a uma abordagem de natureza qualitativa. Houve divulgação entre os docentes e discentes da ETSUS, que foram convidados a participar nos círculos de cultura que seriam formados. Foram convidados os docentes que atuaram em mais de uma turma, por sua experiência, e os alunos que estavam no terceiro módulo do curso, por ser o último, acreditando-se que tinham também maior experiência acumulada.

Para alcançar os objetivos propostos, foram realizados cinco encontros com os docentes e com os discentes, entre março e agosto de 2009. Os quatro primeiros encontros foram organizados com docentes e discentes separadamente. No último encontro, reunimos os dois grupos, num momento de reflexão compartilhada, apresentando os dados coletados nas reuniões anteriores, para discutirmos algumas propostas para o processo de ensino-aprendizagem desenvolvido na ETSUS.

Seguindo Freire (1987) e Gadotti (1991), procuramos propiciar condições favoráveis às dinâmicas dos grupos, reduzindo ao mínimo as intervenções no curso dos diálogos, de modo que a coordenação e facilitação nos círculos de cultura concentraram-se no objetivo de organizar as reuniões, propiciar as informações solicitadas pelos participantes e assegurar o processo reflexivo.

A coleta de dados aconteceu durante os encontros, nos registros escritos pelos participantes, e durante relato de experiências que foram gravadas. No diário de campo, fomos fiéis às palavras utilizadas pelos participantes, registrando, além delas, as expressões e sentimentos percebidos a cada momento. Contamos com o apoio de duas pedagogas, uma em cada encontro, as quais participaram auxiliando no esclarecimento conceitual e de procedimen- 
tos pedagógicos da metodologia problematizadora. Propusemo-nos garantir que o processo de produção de conhecimento acontecesse de forma consciente, construindo um clima de intimidade entre os atores envolvidos, explorando a capacidade de mudança própria do ser humano, colaborando para a quebra de paradigmas, visando à transformação e o aperfeiçoamento dos envolvidos e do processo formativo.

Os temas geradores, que corresponderam a elementos significativos da reflexão, apontados na primeira etapa, tornaram-se categorias do estudo, que foram analisadas a partir da mesma estratégia de coleta de dados, ou seja, codificação, decodificação e desvelamento crítico.

Com a leitura do material produzido nos círculos, foram construídos dois quadros sínteses, um com a classificação das falas dos discentes e o outro com a classificação das falas dos docentes. A partir desses quadros, foi feita a categorização dos temas que foram abordados pelos docentes e discentes, que giraram sempre ao redor de um tema central, objeto desta pesquisa, ou seja, 'O processo de ensino-aprendizagem na formação técnica da ETSUS: contribuições, limites e desafios de uma metodologia participativa.

Das transcrições das gravações obteve-se aproximadamente mil unidades de registro, que representam falas de docentes e discentes. Os participantes docentes receberam nomes próprios fictícios escolhidos por eles, enquanto os alunos escolheram nomes de flores. Participaram 14 alunos e 13 docentes dentre enfermeiros, cirurgiões-dentistas, nutricionista, pedagogos, fonoaudiólogo e normalista superior.

Os participantes foram informados do objetivo e método da pesquisa e assinaram o termo de consentimento livre e esclarecido, no qual se afirmava a possibilidade de desistência, portanto, tendo eles completa liberdade de participação.

Os círculos de cultura transcorreram de modo que as falas, questões e análises pudessem ser livremente expressas. A facilitadora foi apenas uma referência para a condução do processo.

O projeto foi inscrito no Sistema Nacional de Informações sobre Ética em Pesquisa envolvendo Seres Humanos (Sisnep), solicitada a assinatura de anuência da presidente da ETSUS, na folha de rosto gerada pelo Sisnep, e, em seguida, foi encaminhado ao Comitê de Ética para apreciação. Após o projeto ter sido aprovado pelo Comitê de Ética da Universidade do Vale do Itajaí (Univali), iniciamos a coleta de dados.

As reuniões transcorreram de modo afetivo, num processo de acolhimento mútuo entre os participantes, que se manifestaram, exprimindo seus sentimentos e observações sem medo, de modo que todos tiveram a oportunidade de falar e expor seus pensamentos. 


\section{Resultados e discussões}

Os resultados apontaram para a existência de três aspectos importantes que emergiram das falas dos sujeitos. Esses aspectos dizem respeito à necessidade de suporte para melhor manejo da 'problematização', a expressão dos limites existentes entre a teoria e a prática docente, bem como os benefícios que advém quando há opção por esta metodologia.

Da categorização dos dados emergiram as categorias descritas a seguir, que representam também os temas geradores construídos pelos participantes.

\section{Problematização como opção metodológica na visão de docentes e discentes}

Em relação à problematização como opção metodológica, houve concordância em vários pontos entre discentes e docentes, tais como os desafios existentes em relação à aplicação, o fato de esta metodologia oportunizar a participação do discente, contribuir para o seu aprendizado, preparar o discente para mudanças de práticas no serviço. Concordaram que está em processo de construção, mas que já houve avanços, e, por fim, os dois grupos perceberam a necessidade de planejamento.

\footnotetext{
Alguns professores estão bem preparados para trabalhar a 'metodologia problematizadora', mas outros ainda têm que sair daquele método tradicional, pois no modo de falar ele pode até dizer que problematiza, mas quando vem a prática, que decepção (Frésia, Hortência, Lua, Sol, Orquídea, Margarida).

O professor está preocupado com o tempo, com o conteúdo, em como problematizar a realidade e o aluno só quer saber em como vai terminar. $\mathrm{O}$ aluno tem pressa, quer saber logo o resultado, para ir embora. Isso acontece principalmente com os professores que entram no período noturno da semana de bloco (José).
}

Essas falas revelam que tipo de desafios há para a aplicação da problematização como opção metodológica e, na visão dos discentes, quando os docentes se apoiam adequadamente na 'metodologia problematizadora', sentem os reflexos positivos no seu aprendizado e, por isso, eles concordam e acham interessante esta metodologia.

Contudo, os participantes constatam que a atual organização da prática docente na instituição, por não terem vínculo exclusivo, não permite o tempo e espaço para uma reflexão mais profunda sobre os modos de compartilharem os conteúdos com os discentes, de modo a possibilitar processos transformadores. 
O que falta hoje é tempo para o professor planejar, aplicar-se, não estamos mais como no início do processo (Betty, Dermeval, José, Paulo, Rubem).

Falta é esta questão de sentar pedagogicamente. Como docente, venho aqui num período e dou aula, tem o outro período que eu tenho que sentar e planejar, eu tenho que formar a minha aula, na minha cabeça ela tem que estar lá, de onde eu vou sair, onde eu quero chegar e qual o caminho que eu tenho que percorrer para chegar lá (Emilia).

Em resumo, os docentes não têm oportunidades regulares para o planejamento coletivo, nem momentos de educação permanente e, quando o fazem, seu tempo disponível é limitado e o trabalho não é remunerado.

Diante da realidade apresentada, é preciso re-significar a prática do planejamento, resgatando a necessidade e possibilidade para construir coletivamente as estratégias de ensino. A análise das dificuldades didático-pedagógicas apontadas no processo de ensino e aprendizagem em conjunto pode servir para mudanças na orientação e condução da formação profissional. Infelizmente, devido à indisponibilidade em sua agenda, porque a docência não é sua atividade principal, os docentes não trabalham coletivamente.

\section{Aplicação da 'metodologia problematizadora'}

O discente percebe, ainda, a não apropriação da metodologia pelo docente, enquanto o docente apresenta a organização curricular do plano de curso como limitante e o processo avaliativo como desafio. Afirmaram que:

Tem muitos professores que não levam em consideração essa metodologia; chegam, só falam e não escutam o que a gente tem para falar (Hortência, Jasmim, Lua, Orquídea).

Precisamos aprender ainda: como planejar na perspectiva da 'metodologia problematizadora' e a aplicabilidade do ensino por competências (...) Quando o docente não se apropria da metodologia, ele não consegue avaliar por competências, nem consegue aplicar corretamente a problematização (Gaudêncio, Maura, Neusi, Rubem).

O professor, não se apropriando da 'metodologia problematizadora', ao aplicá-la na sala de aula, não tem o resultado esperado através do planejamento, com isso gera a frustração do professor no processo de ensino-aprendizagem (Rubem). 
Os participantes docentes reiteram os limites apontados, especialmente no que se refere à organização curricular e modos de avaliação da aprendizagem, pois ainda se sentem desconcertados diante da necessidade de avaliação e a possibilidade de, ao fazê-lo, tornarem-se incoerentes com a proposta freireana.

Compreendemos que esta situação é delicada, pois há uma tênue área que limita práticas tradicionais de avaliação do conhecimento e avaliação que requer juízo sobre comportamentos, pois esta pode tornar-se veículo de coerção e punição se o docente mantiver o pensamento focado em habilidades e atitudes que considera esperadas no mercado de trabalho. Esta postura está longe de ter a avaliação como oportunidade de aprendizado e redirecionamento das práticas, pois as referências podem ser não só diversas entre docentes como entre discentes sobre o que é adequado e não adequado.

Assim, a problematização carrega consigo uma determinada visão sobre a ética das práticas e relações na área da saúde, assim como em qualquer outra. Se os protagonistas do processo ensino-aprendizagem não procurarem espelhar-se em objetivos de bem comum, ao invés de interesses particulares, a avaliação torna-se um momento aterrador para todos, o que pode gerar pactos nada éticos.

\section{Desafios do processo de ensino-aprendizagem}

Em geral, os participantes expressam os desafios que têm relação com o que denominam 'perfil' do discente e do docente, ou seja, como eles chegam à escola e como isto demonstra suas incapacidades para se inserirem na proposta pedagógica, como se observa nas falas abaixo.

Tinha muito tempo que não estudava, senti dificuldade quando cheguei aqui, tem muito tempo que estou fora da escola, não estou atualizada nas coisas (...). Às vezes, percebia alguma coisa errada na sala de aula, mas não podia questionar, devido ao tempo que estou fora da escola, então ficava calada (Violeta).

Eu tenho dificuldade em falar porque fico nervosa, às vezes eu sei, mas não dou conta de colocar no papel (Sagitariana).

Temos alunos que já terminaram o ensino médio há muito tempo, têm dificuldade de interpretação de textos, escrevem com o português errado mesmo, têm dificuldade de fazer cálculos (Fátima, Gláucia, José).

A diferença de faixa etária dos alunos influencia muito no aprendizado, nós temos turmas com garotos e com pessoas de idade bem mais avançada (Fátima, Gláucia, José). 
Para os discentes é acrescentada a falta de oportunidade para dedicarem mais horas ao estudo. Eles trazem, ainda, reflexos da educação anterior, muitos se sentem sem bases para corresponder às solicitações da nova prática pedagógica, além de que não encontram nos serviços de saúde, nos quais estão inseridos, o apoio dos gestores e dos colegas de serviço e o espaço necessário para aplicarem seus conhecimentos, o que reforça a fragilidade, ainda existente, de integração entre o ensino e o serviço.

Este aspecto reflete uma contingência social ainda posta por um modo de produção interessado na economia de custos com a máxima produtividade, que faz do sistema de saúde um espaço inadequado para a assistência criativa e qualificada, o que demandaria contratação de maior contingente de trabalhadores e mais recursos materiais, se o método assistencial incluir contato mais aproximado e extenso entre profissional e clientela.

O perfil do docente é outro desafio, porque o professor que chega à ETSUS vem de uma formação tradicional e tecnicista, despreparado para trabalhar com a metodologia assumida pela ETSUS.

Ter uma formação na área da saúde e partir para educação já é um desafio, porque nós não somos formados para dar aula, nós somos formados para atuar como profissionais na área da saúde. Começa com o problema de se entender primeiro o processo de ensino-aprendizagem por competência; é difícil de entender (Gaudêncio).

Não estamos preparados para a sala de aula, muito menos para a 'metodologia problematizadora' (Maura).

A partir dessas constatações, podemos observar que há vários determinantes que estão associados e que podem tornar o processo de mudança demorado, desafiador e repleto de instabilidades institucionais e individuais por exigir novas formas de relações entre participantes de processo ensino-aprendizagem.

\section{Fatores que dificultam o processo de ensino-aprendizagem}

Dentre os requisitos que possibilitem a ruptura com métodos tradicionais de ensino-aprendizagem, além do preparo docente e discente, está a reestruturação da escola em termos físicos e organizacionais, de modo que não há somente desafios aos protagonistas do processo. Há, pois, necessidade de adequação institucional para efetivar um processo de ensino-aprendizagem baseado na 'metodologia problematizadora', como se infere das falas abaixo.

Falta acompanhamento da escola para saber se a metodologia está sendo aplicada mesmo, desde a falta de material para estudo quanto da execução das aulas (Orquídea). 
Falta uma pessoa mais capacitada para trabalhar na biblioteca (...). Falta prioridade na biblioteca de quem está estudando para quem está em site de relacionamento (Violeta, Sagitariana, Frésia, Jasmim).

Por não termos a visão do que acontece no pós-escola, não sabemos o resultado que está tendo a formação dos alunos no serviço e isso gera insegurança, se o que nós estamos fazendo está certo, se está trazendo resultados (Rubem).

Falta material para complementar aquilo que os professores dizem (...). Quando a gente chegava aqui, no mês seguinte, não sabia onde estudar, não tinha apostila (Jasmim, Orquídea, Vitória Régia).

Dar aula à noite é um desafio, quando o professor entra no último turno, os alunos já estão desmotivados, não têm vontade de estudar, a gente chega à sala de aula e eles já estão falando que estão cansados, que querem ir embora, ficam pedindo para sair mais cedo (Fátima, Gláucia, José).

Como expressam os participantes, não havendo adequação física e instrumental, o que pode ser uma fragilidade central, os esforços precisam se multiplicar, com maior possibilidade de desgastes físicos e emocionais. Além disso, ao propor essa metodologia, a ETSUS preocupou-se com o preparo do docente, mas se 'esqueceu' de capacitar também os alunos para que eles possam enfrentar essas mudanças, que exigem deles novos comportamentos.

Nos círculos de cultura houve afirmações de que os alunos pedem insistentemente por apostilas, pois foram acostumados, em toda sua trajetória educacional, a acompanhar as aulas por meio dos livros didáticos. Apesar de todas as fragilidades desse tipo de material, tanto os discentes quanto os docentes e equipe pedagógica são defensores da ideia que a ETSUS deve construir o seu material didático, pois esse recurso auxilia o professor em suas atividades didático-pedagógicas.

Também instrumentaliza os discentes para mais estudos no intervalo das três semanas que eles passam longe da ETSUS, uma vez que, por não viverem necessariamente na mesma cidade, optou-se por concentrar as atividades em uma semana intensiva. Entretanto, sinalizam que esse recurso é incompleto e que, ao utilizá-lo, docentes e discentes devem, sempre que possível, adotar uma postura crítica e transformadora, não se limitando a ele.

Todavia, a organização do curso em bloco, aulas diurnas e noturnas, com estrutura inadequada para as aulas práticas, torna-se fator dificultador, além de o docente sentir-se desvalorizado, mal atendido nas suas reivindicações, com salários atrasados e condições de trabalho (recursos pedagógicos) insuficientes.

Esta situação estabelece incoerências nas relações de trabalho que podem comprometer, inclusive, a confiança dos participantes na instituição. 


\section{Fatores que facilitam o processo de ensino-aprendizagem}

Contudo, os participantes observam que houve avanços em relação aos primeiros cursos ofertados, contínuos e permanentes, ainda que sejam insuficientes para que as práticas docentes e discentes em relação à pedagogia problematizadora sejam assumidas com certo grau de conforto.

A escola é bem estruturada, a equipe da escola é ótima e se esforça sempre em melhorar (Violeta, Sagitariana, Frésia, Jasmim).

Eu estive dois anos fora por motivos profissionais e agora estou retornando para a escola e percebo que a escola mudou demais, está cumprindo o seu papel (Paulo).

A metodologia está adequada ao processo. A escola adequou-se ao processo e está crescendo junto com ele (Emilia).

Os discentes percebem ainda que o seu interesse, como ter propósitos com a formação e a valorização profissional, são fatores decisivos que facilitam o processo de ensino-aprendizagem como exemplificado abaixo.

O que eu posso fazer para me empenhar para ser uma boa aluna, para ser uma boa colega de aula para os meus colegas, eu faço. (...) Estou estudando para dar um futuro melhor para os meus filhos; quando queremos algo melhor, temos que correr atrás (Frésia).

Procuro cada vez mais mostrar meu trabalho com a melhor qualidade e ocupar meu espaço para que meu trabalho seja reconhecido e valorizado (Caçula Flor de Liz, Margarida).

A maioria dos cursos da ETSUS organiza-se com turmas heterogêneas, ou seja, com discentes trabalhadores da saúde e discentes que desejam trabalhar na saúde. O desafio de ter discentes que não têm experiência na área do curso pode ser transformado em contribuições e vantagens, porque se o discente do serviço traz consigo suas práticas, por estarem envolvidos no processo, os que não têm experiência entram com maior 'garra' e possuem um embasamento teórico melhor do ensino médio.

Assim, o compromisso pessoal, de docentes e discentes, torna-se um fator que permite melhor apropriação não só do método em si, mas também das possibilidades de apreensão da realidade em movimento constante, que se transforma com a transformação dos indivíduos. 


\section{Considerações finais}

Tivemos a pretensão de conhecer as percepções de docentes e discentes sobre a metodologia problematizadora no processo de ensino e aprendizagem, em relação às necessidades de assistência qualificada. Também desejávamos avaliar elementos facilitadores e dificultadores para a efetiva aplicação desta metodologia.

Para isso, utilizamos o referencial teórico do educador Paulo Freire, por meio do seu itinerário de pesquisa, que consideramos muito importante para auxiliar na compreensão da realidade do estudo e envolver os discentes e docentes na participação desse processo.

Ao refletirmos sobre essa questão, temos várias razões para a aplicação da 'metodologia problematizadora', mas ela não exclui o emprego de técnicas mais conservadoras, quando for o caso de temas lógicos, ou que exigem memorização ou habilidade e destreza, podendo ser aplicada em conteúdos que são intrinsecamente integrados a aspectos socioculturais, que exigem reflexão, crítica, julgamento ético, afeto, como é o caso do processo de adoecimento e de cuidado e cura.

A problematização, quando contextualizada e associando teoria e prática, tem propiciado e desenvolvido o 'aprender a aprender', 'aprender a fazer', 'aprender a ser' e 'aprender a conviver', o que se relaciona com a possibilidade de variadas formas de contato com esses saberes, nem sempre objetivamente compreensíveis.

Por outro lado, compreender um problema da prática e tentar encontrar soluções estimulam a participação, propiciando um espaço de troca de conhecimentos e experiências entre docentes e discentes, em suas buscas pelo aprendizado. Permitem contextualizar o assunto que será estudado, desenvolvendo uma visão crítica e 'empoderamento' do discente, o que contribui para mudanças na prática do serviço e para que a aprendizagem seja significativa.

Essas questões estiveram presentes nos círculos de cultura, não explicitados completamente quando tivemos que sintetizar os dados coletados, para compreendermos os elementos centrais da linguagem dos participantes, quando se referiam aos temas originados na primeira reunião.

Se há inúmeras dificuldades para a plena experiência da metodologia problematizadora, alguns aspectos foram afirmados como consequência do exercício dos participantes de relações mais horizontais. Há valorização do sujeito na relação professor e aluno, motivando e estimulando a autoestima, atendendo aos propósitos de uma educação problematizadora, transformadora, que visa à autonomia do sujeito e a sua emancipação.

Os desafios e limites relacionados com a ETSUS estão pautados nas dificuldades que ela enfrenta para investir em condições melhores de trabalho aos docentes, assim como em ter um quadro fixo de professores, ocasionando 
grande rotatividade. Foram levantadas também questões que envolvem acesso à biblioteca, muitas vezes subutilizada, bem como referências a condições 'inadequadas' da estrutura física da escola para os discentes que passam os três períodos do dia na instituição, além de laboratórios equipados de forma incompleta, de recursos didáticos ainda insuficientes, em geral organizados e não construídos. E, por fim, a falta de acompanhamento do egresso por parte da ETSUS impossibilita conhecer o resultado da formação dos seus discentes e o reflexo dela na prática.

Essa é uma questão também relacionada às políticas de baixo investimento na qualidade de vida das pessoas, exigindo delas um alto grau de envolvimento pessoal, perda de espaço para descanso e convívio, jornadas duplas de trabalho e tantas outras condições que denotam incoerências entre discursos públicos e práticas, entre intenções e gestos, entre desejos e ações políticas.

Sem dúvida, entendemos, a partir dos resultados, que o desafio para a ruptura com métodos tradicionais de ensino-aprendizagem implica inúmeros fatores que tanto dizem respeito às pessoas como à instituição e às macropolíticas, o que nos leva a compreender que requer mais do que 'vontade'.

As posições encontradas expressam uma tendência a generalizações, ou seja, que a vontade de acertar pode ser o elemento chave para a plena aplicação da metodologia preconizada. Mas essas generalizações de conduta precisam considerar que um mesmo ato pode ter nuances diferentes, com graus diferentes de bem ou mal, conforme a circunstância em que ocorre (Leopardi, 2006). Neste caso, a situação demanda desenvolvimento de novas formas de pensar a saúde, assim como novas formas de pensar o ensino. Em outras palavras, a proposta está implicada com um paradigma novo, alicerçado na processualidade dialética, enquanto modo de ver e caminhar no mundo, na consideração da natureza, da vida social e da construção do conhecimento.

Os participantes neste processo encontram-se cotidianamente em mudança, tendo como fundamentos da prática e da reflexão sobre ela a compreensão da realidade e das possibilidades de transformação, num processo histórico.

Qualquer ruptura com tradições necessita de um processo reflexivo que oriente a prática, e uma filosofia de ação, para transformação de comportamentos tecnicistas dos profissionais de saúde, pois implica a consideração de valores e da condição mutante das coisas e das pessoas.

O docente, por vezes, continua fazendo as mesmas velhas coisas, em sala de aula, porque estas representam a forma como aprenderam, trazendo conceitos de 'como ensinar' muito enraizados, como postura epistemológica do professor, determinando o grau de implicação com a metodologia utilizada em sala de aula.

Pouco adianta lutar contra esse modelo hegemônico no campo educacional se, na área da saúde, não forem também quebrados diversos paradigmas 
que dificultam a integralidade das ações e a concretização da filosofia do SUS. Problematizar adquire maior sentido quando as questões paradigmáticas em relação ao objeto saúde-doença são também problematizadas e as demandas em saúde são tratadas na sala de aula.

Além disso, é necessário criar um mecanismo de capacitação e de troca de experiências com os docentes, com carga horária suficiente, relacionada à 'metodologia problematizadora', ampliando a oferta de equipamentos audiovisuais, sempre que possível, para discentes e docentes.

Essas proposições, embora aceitas pelas organizações públicas, não são consideradas estratégicas para a mudança dos conceitos e práticas de ensino e saúde. Isto ocorre, a nosso ver, por deformações históricas na condução da coisa pública, dadas como culturalmente aceitas, sem aproveitamento das críticas e sem continuidade necessária, mesmo com as mudanças pretendidas nas políticas públicas.

Durante a realização desta pesquisa, houve um avanço significativo nas questões relacionadas com a organização institucional e no preparo dos envolvidos para aderirem a essa proposta metodológica. Com a realização dos círculos de cultura, foi garantido ao discente e ao docente um espaço democrático, participativo e reflexivo, onde puderam dialogar com os pares sobre questões relacionadas à sua formação. O diálogo não foi saturado, mas significou o primeiro passo, porque os participantes sentiram-se valorizados, motivados, sujeitos de suas ações, e novas estratégias foram implantadas desde então.

Em relação aos discentes, o grupo tornou-se mais participativo e envolvido no processo de ensino aprendizagem, contagiando o restante da sala e exigindo, dos docentes e dos demais colegas, novas posturas durante as aulas.

Por sua vez, os docentes que participaram dos círculos puderam refletir sobre suas práticas e, segundo eles, perceberam que mudaram nesse processo, aperfeiçoando-se na docência e na metodologia problematizadora.

Por fim, a escola também avançou, uma vez que vários gestores da instituição são docentes e participaram da pesquisa. Admitem que o resultado desta investigação participante acabou por influenciar também os demais gestores e, a partir de então, novas ações foram executadas, fortalecendo os propósitos da formação profissional na saúde.

Dentre os avanços, o planejamento das atividades passou a ser remunerado, a equipe pedagógica foi ampliada, assim como o apoio aos docentes, e elaborado um fluxo para pagamento das horas-aula, de forma a eliminar os atrasos dos salários que eram tão recorrentes.

Acreditamos que, com a realização desta pesquisa, foi impulsionada a dialogicidade entre os sujeitos, contribuindo com reflexões acerca do cotidiano das práticas da docência, na busca de alternativas e soluções para transformá-las para melhor. 
Por outro lado, muitas vezes ingenuamente, pensa-se que a transformação será real quando houver reformas pontuais. Reformas são fundamentais para transformações sociais e subjetivas, mas elas precisam alcançar uma macrocomposição de conjunturas, nas quais o ser humano seja o foco, sempre aliado ao seu ambiente.

Resumen En este texto se presentan los resultados de una investigación cuyo objetivo fue evaluar el desarrollo del proceso de enseñanza y aprendizaje, apoyado por una metodología participativa problematizadora, desde la perspectiva de profesores y alumnos de la Escuela Tocantinense del Sistema Único de Salud Dr. Gismar Gomes para formación de trabajadores del Sistema Único de Salud y para los que buscan el ingreso en este mercado de trabajo. Optamos por el 'itinerario de investigación' del educador Paulo Freire, adoptando los 'círculos de cultura' como contexto de recolección de datos, con tres etapas: construcción de los temas generadores; codificación y decodificación de los temas; y revelación crítica. Se identificaron las temáticas: problematización como opción metodológica, aplicación de la metodología problematizadora, desafíos del proceso de enseñanza-aprendizaje, y factores que dificultan o facilitan el proceso de enseñanza-aprendizaje. Este proceso permitió una mayor aproximación entre los diversos participantes y permitió problematizar aspectos del proceso de enseñanza-aprendizaje de la escuela, favoreciendo una mejor comprensión de esta realidad, permitiendo recontextualizarla con nuevas posibilidades, avances y medios de superación.

Palabras clave educación profesional; formación de recursos humanos; enseñanza-aprendizaje.

\section{Notas}

1 Secretaria Estadual de Saúde, Diretoria de Gestão Profissional, Palmas, Tocantins, Brasil.

$<$ marciacgsiqueira@uol.com.br>

Correspondência: Secretaria Estadual de Saúde, Diretoria de Gestão Profissional, Praça dos Girassóis, Plano Diretor Sul, CEP 77015-007, Palmas, Tocantins, Brasil.

2 Universidade do Vale do Itajaí, Centro de Ciências da Saúde, Itajaí, Santa Catarina, Brasil.

$<$ leopardi@univali.br> 


\section{Referências}

ALMEIDA, Luciana P. G.; FERRAZ, Clarice. A. Políticas de formação de recursos humanos em saúde e enfermagem. Revista Brasileira de Enfermagem, Brasília, v. 61, n. 1, jan./fev. 2008.

BRANDÃO, Carlos R. O que é método Paulo Freire. 20. ed. São Paulo: Brasiliense, 1994.

BORDENAVE, Juan D.; PEREIRA, A. M. Estratégias de ensino-aprendizagem. 25. ed. Petrópolis: Vozes, 2004.

BRASIL. Parecer CNE n. 16/99 - CEB. Aprovado em 5 de outubro de 1999. Disponível em: $<$ www.crmariocovas.sp.gov.br/pdf/diretrizes p0563-0596_c.pdf> Acesso em: 2 jul. 2008.

BRASIL. Ministério da Saúde. Secretaria de Gestão do Trabalho e da Educação na Saúde. Cadernos Recursos Humanos Saúde. Brasília: Ministério da Saúde, 2006. Disponível em: $<$ http://portal.saude.gov.br/portal/arquivos/ pdf/cadernos_rh.pdf> Acesso em: 8 jun. 2008.

CHARLOT, Bernard. Da relação com o saber: elementos para uma teoria. Porto Alegre: Artes Médicas Sul, 2000.

COELHO, Suzana L. B. Pedagogia de problemas. Dicionário da Educação Profissional em Saúde. Fundação Oswaldo Cruz, 2009. Disponível em: <www.epsjv.fiocruz.br/dicionario/ verbetes/pedpro.html>. Acesso em: 12 mar. 2013.

CUTOLO, Luiz. R. A. Modelo biomédico, reforma sanitária e a educação pediátrica. Arquivos Catarinenses de Medicina, Florianópolis, v. 35, n. 4, p. 16-24, 2006.

FREIRE, Paulo. Pedagogia do oprimido. 17. ed. Rio de Janeiro: Paz e Terra, 1987.
FREIRE, Paulo. A importância do ato de ler em três artigos que se completam. 29. ed. São Paulo: Cortez, 1994.

GADOTTI, Moacir. Convite à leitura de Paulo Freire. 2. ed. São Paulo: Scipione, 1991.

LEOPARDI, Maria T. Teoria e método em assistência de enfermagem. Florianópolis: Soldasoft, 2006.

MAHONEY, Abigail A.; ALMEIDA, Laurinda R. Afetividade e processo ensino-aprendizagem: contribuições de Henri Wallon. Psicologia da Educação, São Paulo, v. 20, p. 11-30, 1. sem., 2005.

SAUPE, Rosita; BRITO, Valdete H.; GIORGI, Maria D. M. Utilizando as concepções do educador Paulo Freire no pensar e agir da enfermagem. In: SAUPE, Rosita (org.). Educação em enfermagem: da realidade construída à possibilidade em construção. Florianópolis: UFSC, Repensul, 1998. p. 245-272.

SIQUEIRA, Márcia C. G. O processo de ensino-aprendizagem na formação técnica dos trabalhadores em saúde: contribuições, limites e desafios de uma metodologia participativa. 2009. 181f. Dissertação (Mestrado Profissional em Saúde e Gestão do Trabalho) Universidade do Vale do Itajaí, Itajaí, Santa Catarina, 2009

SORIO, Rita E. R. Educação profissional em saúde no Brasil: a proposta das escolas técnicas de saúde do Sistema Único de Saúde. v. 2, n. 5. Formação. Brasília, DF: Ministério da Saúde; Profae, maio 2002.

Recebido em 14/06/2011

Aprovado em 17/10/2014 